\title{
Prevalence of Mycoplasma genitalium infection in women with bacterial vaginosis
}

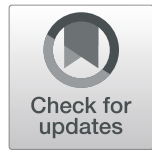

Melinda B. Nye ${ }^{1}$, Ayla B. Harris ${ }^{1}$, Amanda J. Pherson ${ }^{1}$ and Charles P. Cartwright ${ }^{2^{*}}$

\begin{abstract}
Background: Bacterial vaginosis (BV) is a common condition in reproductive-age women and is known to be positively associated with risk of acquisition of sexually transmitted infections (STI) such as chlamydia and gonorrhea. Mycoplasma genitalium is an emerging STI that has been linked to increased risk of pelvic inflammatory disease, adverse pregnancy outcomes and infertility. In the present study we sought to examine whether women diagnosed with symptomatic BV were at increased risk of having concurrent infection with Mycoplasma genitalium.

Methods: We used a novel PCR-based assay (ResistancePlus MG; SpeeDx Pty. Ltd., Sydney, Australia) to determine the prevalence of Mycoplasma genitalium infection and 23S rRNA macrolide-resistance mediating mutations (MRMM) in a cohort of 1532 women presenting with symptoms of vaginitis.
\end{abstract}

Results: M. genitalium was detected in 4.0\% (62/1532) of samples with $37.1 \%$ (23/62) harboring MRMMs. The prevalence of M. genitalium infection in subjects with BV was significantly higher than in subjects with non-BV vaginitis (7.0\% v 3.6\%; OR $=1.97$ (95\% Cl: 1.14-3.39).

Conclusions: Prevalence of M. genitalium infection is associated with BV in women with symptomatic vaginitis. Improved management of BV is needed as a component of STI prevention strategies.

Keywords: Bacterial vaginosis, Mycoplasma genitalium, Prevalence, Association, Antimicrobial resistance

\section{Background}

Although Mycoplasma genitalium was first identified as a potential etiologic agent of non-gonococcal urethritis (NGU) in the early 1980's [1], it was not until the advent of molecular amplification testing that the true significance of M. genitalium as a sexually transmitted infection (STI) could be accurately elucidated. Associations between $M$. genitalium and acute and chronic conditions in women, including cervicitis [2], pelvic inflammatory disease (PID) $[3,4]$ infertility $[3,4]$ and preterm birth [3, 4] have been established. In response to these findings, published guidelines for the management of STIs continue to be revised to reflect the need for assessment of M. genitalium in patients at risk of STI [5-7].

\footnotetext{
* Correspondence: charlesc@speedx.com.au

${ }^{2}$ SpeeDx Pty. Ltd., Sydney, Australia

Full list of author information is available at the end of the article
}

Bacterial vaginosis (BV) is the most prevalent cause of vaginitis symptoms in reproductive age women [8] and has been linked to increased risk of acquisition of other STIs, including Human Immunodeficiency Virus (HIV) [9], Chlamydia trachomatis [10] and Neisseria gonorrhoeae [10]. Testing for these STI agents in women diagnosed with symptomatic BV is recommended [7]. Only limited data is available on the prevalence and incidence of M. genitalium infection in women with BV, and more information is clearly needed. In a large study of asymptomatic, sexually active, university students conducted in the United Kingdom [11], overall M. genitalium prevalence was 3.3\% (78/2378), this was, however, substantially elevated $(6.5 \% \mathrm{v} 2.4 \%)$ in women with BV. In a smaller US study of 400 female patients attending an urban STI clinic, an M. genitalium prevalence of $17.5 \%$ (70/400) was observed and no association between $M$. genitalium and BV was identified [12]. 
The present study adds to the relatively limited body of data [11-15] in which the prevalence of $M$. genitalium has been determined in women with BV. In this investigation we used a novel multiplexed PCR assay [16] (ResistancePlus ${ }^{\circ}$ MG, SpeeDx Pty. Ltd., Sydney, Australia) to identify M. genitalium positive samples, and detect macrolide-resistance, in a large cohort of women with vaginitis [17].

\section{Methods}

Residual vaginal swab samples were available for analysis from 1532 of the 1579 women originally enrolled in a previously published clinical validation study of a molecular assay for BV (NS-002) [17]. All subjects were aged between 18 and 50 and had presented at 1 of 5 locations in the US between August 2016 and March 2017 with symptoms of vaginitis. The sample series consisted of 2 vaginal swab samples collected in liquid Amies transport medium (Copan Diagnostics) that were used for Gram stain preparation and yeast culture, 1 vaginal swab sample collected in the Affirm ${ }^{\text {tm }}$ VPIII transport system (Becton-Dickinson), and 2 APTIMA $^{\circ}$ vaginal swab collections (Hologic). One of the APTIMA collections was used for performance of nucleic-acid amplification testing including assays for M. genitalium, BV, Trichomonas vaginalis and Candida spp.; the second APTIMA $^{\circ}$ was retained for microbiome analysis. Samples were analyzed for potential etiologies of vaginitis as follows:

\section{Bacterial vaginosis (BV)}

Vaginal discharge was analyzed on each subject at enrollment according to Amsel criteria [18] with an 'Amsel positive' sample having at least 3 positive results; a $\mathrm{pH}$ value of greater than 4.5, a positive "whiff test" ("fishy' odor upon addition of $\mathrm{KOH}$ ), presence of clue cells upon microscopic evaluation, and thin, homogeneous vaginal discharge. Analysis by quantitative Gram-stain was performed at a central reference laboratory as described previously [19] and scored using the Nugent criteria [20]. Only samples that generated positive Nugent scores [7-10] and were positive by Amsel criteria were deemed to be BV positive.

\section{Vulvovaginal candidiasis (VVC)}

The presence of Candida spp. in the samples was determined by use of 2 multiplexed PCR assays that enable detection and differentiation of C. albicans and C. glabrata (CAN-PCR) or C. lusitaniae, C. krusei, C. parapsilosis gp, and C. tropicalis (CAN2-PCR). Primer sequences for the CAN-PCR assay were disclosed in Cartwright et al. (2013) [21] and for CAN2-PCR are shown in Supplemental Table 1. Confirmation of the identity of Candida spp. detected in samples using PCR was performed by sequence analysis of the 18S rRNA-28S rRNA internally transcribed spacer (ITS) region.

\section{Trichomonas vaginitis (TV)}

Trichomonas-containing samples were identified using the FDA-cleared APTIMA ${ }^{\circ}$ Trichomonas vaginalis NAAT assay (Hologic Inc., San Diego, CA) with testing being performed according to the manufacturer's instructions.

Testing for M. genitalium was performed using the ResistancePlus ${ }^{\circ}$ MG (RPMG) assay. RPMG is a recently developed multiplexed PCR assay that enables simultaneous detection of $M$. genitalium DNA and a cluster of mutations in the 23S rRNA gene (A2058G, A2059G, A2058T, A2058C, A2059C) associated with macrolide resistance in this organism [16]. Previous studies have reported favorably on the performance of RPMG when compared with reference molecular methods for detection and resistance determination in M. genitalium [16]. Nucleic-acid was extracted from APTIMA vaginal swab collections $(200 \mu \mathrm{L})$ using the MagNA Pure 96 System (Roche Molecular Diagnostics, Indianapolis, IN) as previously described with $200 \mu \mathrm{L}$ input and $100 \mu \mathrm{l}$ elution volumes. RPMG assays were performed in $20 \mu \mathrm{L}$ reaction volumes using $5 \mu \mathrm{L}$ of eluted nucleic acid using an ABI 7500 Fast Dx instrument (Thermo Fisher Scientific, Waltham, MA) with amplification parameters provided by the assay manufacturer. Three channels were used for product detection; one for $M$. genitalium detection based on amplification of the MgPa gene, a second for stacked detection of $23 \mathrm{~s}$ rRNA macrolide-resistance mediating mutations (MRMM), and the third for detection of an internal control target added prior to nucleic-acid extraction. Data reduction was performed using the FastFinder analysis software application (UgenTec NV, Hasselt, Belgium) provided by SpeeDx.

Statistical analyses were performed using the MedCalc ${ }^{\circ}$ software suite (www.medcalc.org, Ostend, Belgium).

\section{Results}

The overall prevalence of $M$. genitalium in the study cohort was $4.0 \%(62 / 1532)$ of which $37.1 \%(23 / 62)$ possessed MRMM. Univariate analyses of M. genitalium prevalence by microbiologic, clinical and demographic characteristics is shown in Table 1. M. genitalium ( $p$ value $=.020$ ) infections were significantly more common in women with BV than those without this condition $(\mathrm{OR}=1.97$ (95\% CI: 1.14-3.39); Table 1). M. genitalium prevalence was not, however, associated with the other etiologies of vaginitis (VVC and TV). In addition, independent analysis of the two diagnostic approaches for identification of BV showed a positive association with positive Nugent scores [7-10] but not with positive Amsel results (Table 1). The prevalence of $M$. genitalium in subjects self-identified as African-American was 
Table 1 Characteristics of women enrolled in NS-002 study and association with prevalent $M$. genitalium infection

\begin{tabular}{|c|c|c|c|}
\hline & M. genitalium positive & & \\
\hline Characteristic & $(\boldsymbol{n}=62)$ & $\boldsymbol{p}$-value & OR $(95 \% \mathrm{Cl})$ \\
\hline \multicolumn{4}{|l|}{ BV } \\
\hline Positive (307) & $20(7.0 \%)$ & & \\
\hline Negative (1225) & $42(3.6 \%)$ & 0.020 & $2.12(1.10-3.10)$ \\
\hline \multicolumn{4}{|l|}{ Amsel Criteria } \\
\hline Positive (464) & $22(5.0 \%)$ & & \\
\hline Negative (1068) & $40(3.7 \%)$ & 0.252 & $1.37(0.80-2.32)$ \\
\hline \multicolumn{4}{|l|}{ Nugent Score } \\
\hline Positive (469) & $27(5.8 \%)$ & & \\
\hline Negative (1063) & $35(3.3 \%)$ & 0.042 & $1.84(1.21-3.09)$ \\
\hline \multicolumn{4}{|l|}{ vvc } \\
\hline Positive (274) & $13(4.7 \%)$ & & \\
\hline Negative (1258) & 49 (3.9\%) & 0.536 & $1.22(0.66-2.28)$ \\
\hline \multicolumn{4}{|l|}{ TV } \\
\hline Positive (89) & $5(5.6 \%)$ & & \\
\hline Negative (1443) & $57(4.0 \%)$ & 0.462 & $1.42(0.56-3.64)$ \\
\hline \multicolumn{4}{|l|}{ Race/Ethnicity } \\
\hline $\begin{array}{l}\text { African-American } \\
\text { (516) }\end{array}$ & $33(6.4 \%)$ & & \\
\hline $\begin{array}{l}\text { Non-African } \\
\text { American (1016) }\end{array}$ & $29(2.9 \%)$ & 0.002 & $2.25(1.35-3.73)$ \\
\hline \multicolumn{4}{|l|}{ Age } \\
\hline$<25$ years (471) & $32(6.8 \%)$ & & \\
\hline$\geq 25$ years (1061) & $30(2.8 \%)$ & $<0.001$ & $2.40(1.44-4.00)$ \\
\hline
\end{tabular}

Abbreviations: $B V$ Bacterial vaginosis, WVC Vulvovaginal candidiasis, $T V$ Trichomonas vaginitis, $O R$ Odds Ratio, $\mathrm{Cl}$ Confidence Interval

significantly higher than in non-African American subjects $(6.4 \%$ v $2.9 \%, p=0.002$; OR: 2.33$)$ and in subjects under age 25 versus those 25 and older $(6.8 \%$ v $2.8 \%$, $p<0.001$; OR: 2.40). BV, African-American race, and age $<25$ all remained independently associated with increased M. genitalium prevalence in multivariate analysis (Table 2).

The presence of MRMMs was identified in a significant minority $37.1 \%(23 / 62)$ of the M. genitalium positive samples using the ResistancePlus MG PCR assay. The prevalence of MRMM-harboring $M$.

Table 2 Results of logistic regression analysis including characteristics identified as associated with prevalent $M$. genitalium infection by univariate analysis

\begin{tabular}{lll}
\hline Characteristic & $\boldsymbol{p}$-value & AOR $(95 \% \mathrm{Cl})$ \\
\hline BV (Positive $\vee$ Negative) & 0.031 & $1.81(1.04-3.04)$ \\
Age (< 25 years $\vee \geq 25$ years) & 0.004 & $2.52(1.50-4.22)$ \\
Race (AA vs non-AA) & 0.016 & $1.94(1.13-3.36)$
\end{tabular}

Abbreviations: AA African-American, AOR Adjusted Odds Ratio, $\mathrm{Cl}$ Confidence Interval genitalium was slightly higher in women without concurrent BV (41.4\% vs 33.3\%) but this was not statistically significant.

\section{Discussion}

The prevalence of M. genitalium infection was significantly higher in women presenting with vaginitis caused by BV, similar results to those reported by Oakeshott and colleagues who were the first to report an association between M. genitalium and asymptomatic BV [11]. We identified an OR of M. genitalium in BV-positive vs BV-negative women of 1.97 , a value of 2.73 was reported for this parameter in the Oakeshott et al. study [11]. We also demonstrated that this association is related to dysbiosis and not clinical manifestations of BV since positive Nugent Gram-stain scores alone were independently associated with $M$. genitalium prevalence (Table 1). Since the present study was conducted retrospectively it was not possible to determine the impact of BV on incidence of M. genitalium infection. A recently published prospective study, however, found no evidence that therapeutic intervention in women with asymptomatic BV impacted $M$. genitalium incidence during a 12month follow-up period [15]. Whether this finding reflects a true lack of causality between vaginal dysbiosis and $M$. genitalium acquisition or is indicative of failure of therapeutic intervention to eliminate BV could not be determined [15]. It is conceivable that the presence of a vaginal microbiome consistent with BV merely serves as a non-specific marker for selecting populations at higher risk of infection with other STI including $M$. genitalium or, somewhat less likely, that persistence of a dysbiotic microbiome is more likely if patients are co-infected with M. genitalium. Additional studies will hopefully resolve these questions.

In the study of Sena et al. [15], black race, age $<21$ years, and prior-pregnancy were identified as being significantly associated with prevalent $M$. genitalium infection in women with BV. Only limited demographic data was collected on subjects in the present study but we were able to assess associations between race, age and prevalence of $M$. genitalium infection. Similar associations between African-American race $(\mathrm{OR}=2.33)$ and age $(<25$ years old vs 25 years old or older; $\mathrm{OR}=2.40)$ were identified in our study population as seen in that of Sena et al. [15]. The potentially confounding influence of race and age on the observed association between $\mathrm{BV}$ and M. genitalium prevalence was assessed using logistic regression analysis. Under multivariate analysis, however, BV remained significantly associated with prevalent $M$. genitalium infection as did African-American race and age $<25$ years (Table 2). The lack of an association between clinical manifestations of $\mathrm{BV}$, as assessed by Amsel scores, and M. genitalium prevalence (Table 1) 
was not unexpected since positive associations between BV and M. genitalium have previously been demonstrated in entirely asymptomatic populations [11, 15]. Limitations notwithstanding, the findings presented here and in the study of Sena et al. [15] suggest that the presence of BV represents a significant risk factor for acquisition of $M$. genitalium and logically, therefore, that women with untreated BV are at elevated risk of developing symptomatic $M$. genitalium infections and, or, transmitting this organism to their sexual partners. Given that testing for $M$. genitalium in asymptomatic populations is not currently recommended, improved diagnosis and management of BV may be a useful approach to mitigating these risks.

Importantly, by using a novel $M$. genitalium NAAT assay we were able to determine not merely the prevalence of $M$. genitalium in the study population but also the frequency with which MRMM were present in $M$. genitalium positive samples. MRMMs were identified in a significant minority (37.1\%) of $M$. genitalium infections, a result somewhat higher than the $30.8 \%$ reported previously in a cohort of females with asymptomatic $M$. genitalium infection in the US [22]. Although azithromycin remains recommended first-line therapy for M. genitalium in the US [7], that recommendation pre-dates much of our understanding of the prevalence of macrolide-resistance in this organism and is likely to change in the relatively near future. For efforts at curtailing resistance to be successful, however, clearly consideration must be given to the importance of potential reservoirs of resistant organisms such as the vaginal milieu of asymptomatic women with dysbiotic microbiota.

\section{Conclusions}

The present study extends previous findings regarding the epidemiology of $M$. genitalium infection, demonstrating that prevalence of infection with this organism is associated with BV in women with vaginitis. The results presented here demonstrate that improved diagnosis and management of vaginitis due to BV may prove to useful in decreasing prevalence and transmission of pathogenic organisms like M. genitalium.

\section{Supplementary information}

Supplementary information accompanies this paper at https://doi.org/10 1186/s12905-020-00926-6.

Additional file 1: Table S1. Primer sequences used in the CAN2-PCR assay for Candida krusei, Candida lusitaniae, Candida parapsilosis gp. and Candida tropicalis.

\section{Abbreviations}

AOR: Adjusted odds ratio; BV: Bacterial vaginosis; HIV: Human immunodeficiency virus; MRMM: Macrolide-resistance mediating mutations; NGU: Non-gonococcal urethritis; OR: Odds ratio; PID: Pelvic inflammatory disease; RPMG: ResistancePlus MG; STI: Sexually transmitted infection; TV: Trichomonas vaginitis; WC: Vulvovaginal candidiasis

\section{Acknowledgements}

None.

\section{Authors' contributions}

All authors have read and approved the final manuscript. The specific contributions of each author to the final manuscript were as follows: MBN participated in study design, data review, manuscript preparation. $\mathrm{ABH}$ performed testing of specimens, compilation and analysis of datasets. AJP performed study data management and assisted with analysis of datasets. CPC participated in study design, review of final datasets and manuscript preparation.

\section{Funding}

No external sources of funding were obtained to support the study.

\section{Availability of data and materials}

All data generated or analyzed during this study are included in this published article and supplementary information files.

\section{Ethics approval and consent to participate}

The present study was conducted retrospectively using non-identifiable biospecimens. As such it was not necessary to obtain informed consent or IRB approval for the study under US Federal Law (45 CFR Part 46: Basic HHS Policy For Protection of Human Subjects).

Consent for publication

Not applicable.

\section{Competing interests}

Charles P. Cartwright is an employee of SpeeDx Pty. Ltd., the manufacturer of the ResistancePlus MG assay used in the current study.

\section{Author details}

${ }^{1}$ Center for Esoteric Testing, Laboratory Corporation of America ${ }^{\circledR}$ Holdings, Burlington, North Carolina, USA. ${ }^{2}$ SpeeDx Pty. Ltd., Sydney, Australia.

Received: 6 January 2020 Accepted: 16 March 2020

Published online: 26 March 2020

\section{References}

1. Tully JG, Taylor-Robinson D, Cole RM, Rose DL. A newly discovered mycoplasma in the human urogenital tract. Lancet. 1981;317:1288-91.

2. Gaydos C, Maldeis NE, Hardick A, et al. Mycoplasma genitalium as a contributor to the multiple etiologies of cervicitis in women attending sexually transmitted disease clinics. Sex Transm Dis. 2009;36:598-606.

3. Anagrius C, Lore B, Jensen JS. Mycoplasma genitalium: prevalence, clinical significance, and transmission. Sex Transm Infect. 2005;81:458-62.

4. Lis R, Rowhani-Rahbar A, Manhart LE. Mycoplasma genitalium infection and female reproductive tract disease: a meta-analysis. Clin Infect Dis. 2015;61: 418-26.

5. Australian STI management guidelines for use in primary care: Mycoplasma genitalium. Australasian Sexual Health Alliance (www.sti.guidelines.org.au). 2018.

6. Soni S, Horner P, Rayment M, et al. British Association for Sexual Health and HIV national guideline for the management of infection with Mycoplasma genitalium (www.bassh.org/guidelines). 2018.

7. Workowski KA, Bolan GA. Sexually transmitted diseases treatment guidelines, 2015: MMWR Recomm. Rep. 2015;64:1-137.

8. Kenyon C, Colebunders R, Crucitti T. The global epidemiology of bacterial vaginosis: a systematic review. Am J Obstet Gynecol. 2013;209:505-23.

9. Atashili J, Poole C, Ndumbe PM, et al. Bacterial vaginosis and HIV acquisition: a meta-analysis of published studies. AIDS. 2008;22:1493-501.

10. Gallo MF, Macaluso M, Warner $L$, et al. Bacterial vaginosis, gonorrhea, and chlamydial infection among women attending a sexually transmitted disease clinic: a longitudinal analysis of possible causal links. Ann Epidemiol. 2012;22:213-20 
11. Oakeshott P, Aghaizu A, Hay P, et al. Is Mycoplasma genitalium in women the "new chlamydia?" a community-based prospective cohort study. Clin Infect Dis. 2010;51:1160-6.

12. Lillis RA, Martin DH, Nsuami MJ. Mycoplasma genitalium infections in women attending a sexually transmitted disease clinic in New Orleans. Clin Infect Dis. 2019:459-65.

13. Palmer HM, Gilroy CB, Claydon EJ, et al. Detection of Mycoplasma genitalium in the genitourinary tract of women by the polymerase chain reaction. Int J STD \& AIDS. 1991;2:261-3.

14. Keane EA, Thomas J, Gilroy CB, et al. The association of Mycoplasma hominis, Ureaplasma urealyticum and Mycoplasma genitalium with bacterial vaginosis: observations on heterosexual women and their male partners. Int. J. STD \& AIDS. 2000;11:356-60.

15. Sena AC, Lee JY, Schwebke J, et al. A silent epidemic: the prevalence, incidence and persistence of Mycoplasma genitalium among young, asymptomatic high-risk women in the United States. Clin Infect Dis. 2018;67: 73-9.

16. Tabrizi SN, Su J, Bradshaw CS, et al. Prospective evaluation of ResistancePlus MG, a new multiplex quantitative PCR assay for detection of Mycoplasma genitalium and macrolide resistance. J Clin Microbiol. 2014;55:1915-9.

17. Cartwright $C P$, Pherson $A J$, Harris $A B$, et al. Multicenter study establishing the clinical validity of a nucleic-acid amplification-based assay for the diagnosis of bacterial vaginosis. Diagn Micro Infect Dis. 2018;92:173-8.

18. Amsel $R$, Totten PA, Speigel CA, et al. Nonspecific vaginitis. Diagnostic criteria and microbial and epidemiologic associations. Am. J. Med. 1983;74 $14-22$.

19. Cartwright CP, Lembke BD, Ramachandran $K$, et al. Development and validation of a semiquantitative, multitarget PCR assay for the diagnosis of bacterial vaginosis. J Clin Microbiol. 2012;50:2321-9.

20. Nugent RP, Krohn MA, Hillier SL. Reliability of diagnosing bacterial vaginosis is improved by a standardized method of gram stain interpretation. J Clin Microbiol. 1991;29:297-301.

21. Cartwright CP, Lembke BD, Ramachandran K, et al. Comparison of nucleic acid amplification assays with BD affirm VPIII for diagnosis of vaginitis in symptomatic women. J Clin Microbiol. 2013:3694-9.

22. Getman D, Jiang A, O'Donnell M, Cohen S. Mycoplasma genitalium prevalence, coinfection, and macrolide antibiotic resistance frequency in a multicenter clinical study cohort in the United States. J. Clin. Microbiol. 2016:54:2278-83.

\section{Publisher's Note}

Springer Nature remains neutral with regard to jurisdictional claims in published maps and institutional affiliations.

Ready to submit your research? Choose BMC and benefit from:

- fast, convenient online submission

- thorough peer review by experienced researchers in your field

- rapid publication on acceptance

- support for research data, including large and complex data types

- gold Open Access which fosters wider collaboration and increased citations

- maximum visibility for your research: over $100 \mathrm{M}$ website views per year

At $\mathrm{BMC}$, research is always in progress.

Learn more biomedcentral.com/submissions 